\title{
Erratum to: Apparent competition between major pests reduces pest population densities on tomato crop, but not yield loss
}

\author{
Coline C. Jaworski ${ }^{1,2}$ (1) Anaïs Chailleux ${ }^{2,3} \cdot$ Philippe Bearez $^{2} \cdot$ Nicolas Desneux $^{2}$
}

Published online: 23 October 2015

(C) Springer-Verlag Berlin Heidelberg 2015

\section{Erratum to: J Pest Sci}

DOI 10.1007/s10340-015-0698-3

Figure $3 b$ and $c$ legend was published incorrectly in the original publication of the article.
The correct figure legend for Fig. $3 b$ and $c$ is given below

The online version of the original article can be found under doi:10.1007/s10340-015-0698-3.

Coline C. Jaworski

jaworskicoline@yahoo.fr

$\square$ Nicolas Desneux

nicolas.desneux@sophia.inra.fr

1 Laboratoire Evolution et Diversité Biologique, CNRS,

Université de Toulouse (UPS), ENFA, UMR5174, 118 route

de Narbonne, 31062 Toulouse, France

2 INRA (French National Institute for Agricultural Research), Univ. Nice Sophia Antipolis, CNRS, UMR 1355-7254,

Institut Sophia Agrobiotech, 06903 Sophia Antipolis, France

3 Cirad, UPR HortSys, 34398 Montpellier, France 


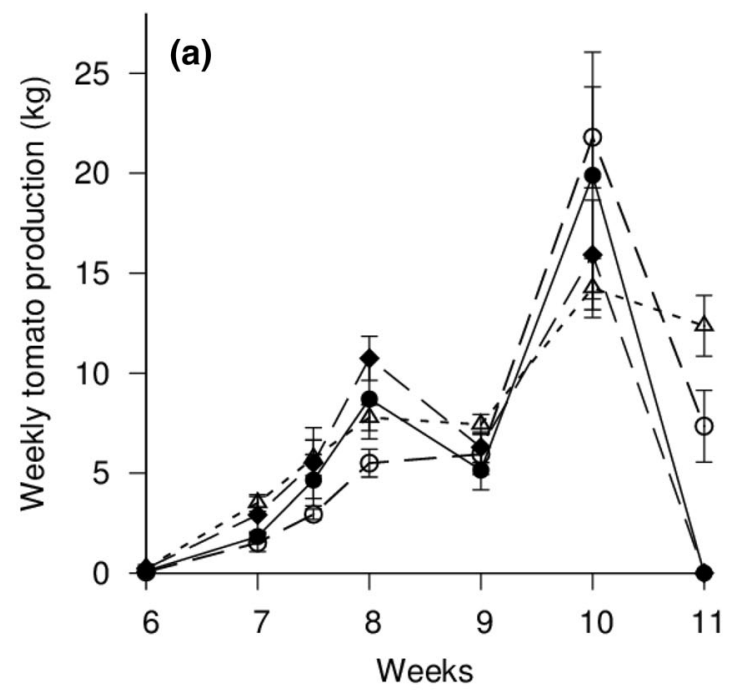

(a)

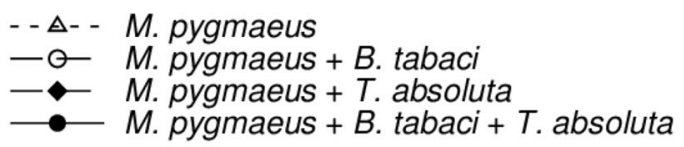

(b) and (c)

$\square$ damaged by B. tabaci

$\square$ damaged by B. tabaci and T. absoluta

$\square$ damaged by T. absoluta

\section{$\mathrm{B}+\mathrm{T} \quad$ M. pygmaeus + B. tabaci + T. absoluta \\ B $\quad$ M. pygmaeus + B. tabaci \\ T M. pygmaeus + T. absoluta}
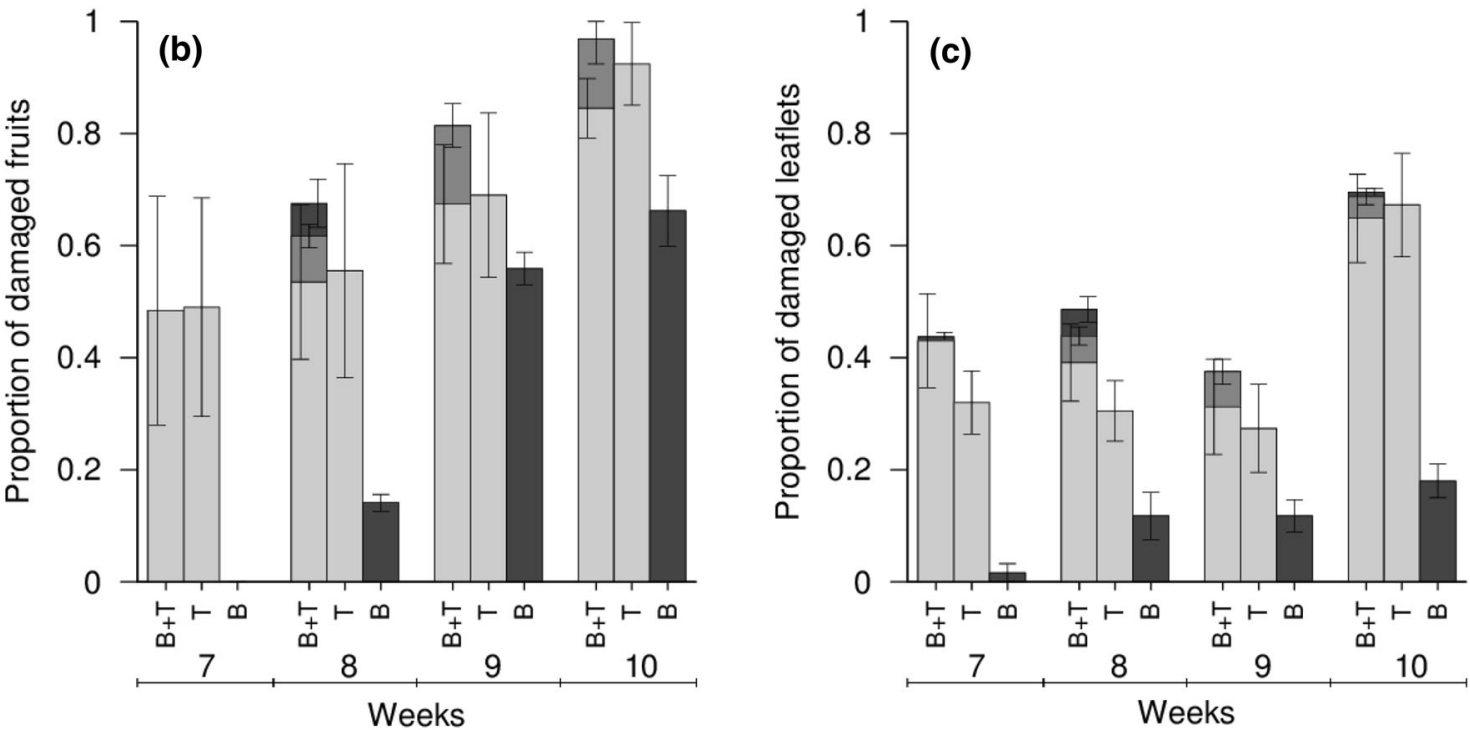

Fig. 3 Plant and fruit damage due to pests. Impacts of the presence of the prey species B. tabaci and T. absoluta (alone or together) on

plants $\pm \mathrm{SE} ; \quad N=4$ ); (b) the proportion of damaged fruits (mean $\pm \mathrm{SE} ; N=4$ ); and (c) the proportion of damaged leaflets (mean $\pm \mathrm{SE} ; N=16$ ) 